(72 UI). Treatment with corticosteroids was impossible because of the patient's psychiatric instability. Hydroxychloroquine treatment $\left(400 \mathrm{mg} \cdot\right.$ day $\left.^{-1}\right)$ was then initiated. A significant, but only partial, clinical, radiological and functional improvement ensued, with a secondary relapse despite good observance.

In July 2009, the patient's condition worsened with PFT results comparable to those at first presentation (fig. 1). Treatment with azathioprine $\left(150 \mathrm{mg} \cdot \mathrm{day}^{-1}\right)$ was then started as hydroxychloroquine was withdrawn. This treatment allowed a significant gradual clinical, radiological and functional improvement (fig. 2), with almost normalised PFTs by December 2011 (fig 1). SACE level also normalised. Only stable fibrotic chest CT lesions and DL,CO abnormalities persisted. Treatment efficacy and tolerance were still excellent after 17 months and a reduction of azathioprine $\left(100 \mathrm{mg} \cdot \mathrm{day}^{-1}\right)$ was initiated.

CBD is a granulomatous disease due to beryllium exposure in genetically susceptible individuals. CBD treatment relies on stopping beryllium exposure and corticosteroid therapy [8]. Despite frequent responses to such treatment, several limits are often observed, as in sarcoidosis, such as corticosteroid dependence, severe side-effects and, sometimes, pulmonary fibrosis progression.

To date, in CBD, unlike sarcoidosis, no therapy other than corticosteroids has been considered. We report the first case of a successful azathioprine treatment in a patient who had a contraindication to the use of corticosteroids. Azathioprine can also be used in sarcoidosis treatment as a corticosteroid-sparing agent thanks to its strong and delayed suppressive effect on Tlymphocytes proliferation and activation [9]. We have been able to demonstrate the efficacy of azathioprine in treatment of CBD allowing prolonged clinical, functional and radiologic control. Consequently, azathioprine could be considered in CBD in the presence of contraindication or when there is poor tolerance to corticosteroids, or perhaps as a corticosteroid sparing agent when prolonged high doses are necessary. Interestingly, we observed a partial and temporary efficacy of hydroxychloroquine, a drug known to reduce antigen presentation that also works in some sarcoidosis patients.

Hélène Salvator*, Thomas Gille ${ }^{\#, \text { }}$, Aurélie Hervé*, Camille Bron*, Christine Lamberto ${ }^{\#, \uparrow}$, Dominique Valeyre ${ }^{*}$, *Dept of Respiratory Diseases, Avicenne University Hospital, AP-HP, "Dept of Physiology, Avicenne University Hospital,
AP-HP, and "University Paris 13, PRES Sorbonne Paris Cité, EA2363, Bobigny, France.

Correspondence: H. Salvator, Dept of Respiratory Diseases, Avicenne University Hospital, AP-HP, 93000 Bobigny, France. E-mail: hsalvator@yahoo.fr

Statement of Interest: Statement of interest for T. Gille and D. Valeyre can be found at www.erj.ersjournals.com/site/misc/ statements.xhtml

\section{REFERENCES}

1 Richeldi L, Sorrentino R, Saltini C. HLA-DPB1 glutamate 69: a genetic marker of beryllium disease. Science 1993; 262: 242-244.

2 Marchand-Adam S, Guillon F, Brauner M, et al. Berylliose pulmonaire chronique (2e partie). Pathogenie, expression clinique, prevention et legislation [Chronic beryllium disease: a model of interaction between environmental exposure and genetic predisposition. Pathogenesis and clinical features (Part 2)]. Rev Mal Respir 2005; 22: 271-287.

3 Marchand-Adam S, Valeyre D. Berylliose pulmonaire chronique: un modele d'interaction entre environnement et predisposition genetique (1re partie). Mineralogie, toxicologie, epidemiologie et facteurs de risque [Chronic pulmonary berylliosis: a model of interaction between environment and genetic predisposition (Part 1). Mineralogy, toxicology, epidemiology and risk factors]. Rev Mal Respir 2005; 22: 257-269.

4 Fireman E, Haimsky E, Noiderfer M, et al. Misdiagnosis of sarcoidosis in patients with chronic beryllium disease. Sarcoidosis Vasc Diffuse Lung Dis 2003; 20: 144-148.

5 Müller-Quernheim J, Gaede KI, Fireman E, et al. Diagnoses of chronic beryllium disease within cohorts of sarcoidosis patients. Eur Respir J 2006; 27: 1190-1195.

6 Marchand-Adam S, El Khatib A, Guillon F, et al. Short- and longterm response to corticosteroid therapy in chronic beryllium disease. Eur Respir J 2008; 32: 687-693.

7 Sood A, Beckett WS, Cullen MR. Variable response to long-term corticosteroid therapy in chronic beryllium disease. Chest 2004; 126: 2000-2007.

8 Sprince NL, Kanarek DJ, Weber AL, et al. Reversible respiratory disease in beryllium workers. Am Rev Respir Dis 1978; 117: 1011-1017.

9 Müller-Quernheim J, Kienast K, Held M, et al. Treatment of chronic sarcoidosis with an azathioprine/prednisolone regimen. Eur Respir J 1999; 14: 1117-1122.

\title{
Do tertiary paediatric hospitals deal with the same spectrum of paediatric pulmonary hypertension as multicentre registries?
}

\section{To the Editor:}

Although national [1-5] and international paediatric registries for pulmonary hypertension $(\mathrm{PH})[6,7]$ have been published recently, inclusion criteria and, therefore, the distribution of aetiologies and severity of cases have not always been comparable [8]. 
In order to determine possible differences between registries, we have compared the aetiologies of confirmed $\mathrm{PH}$ of prevalent versus incident cases of $\mathrm{PH}$ in our own large database (in a tertiary paediatric hospital), and compared these to recently reported large multinational registries.

According to pre-specified protocols, any children with clinical symptoms or at risk of $\mathrm{PH}$ at our centre were referred for echocardiography. If tricuspid regurgitation velocity was $>2.8 \mathrm{~m} \cdot \mathrm{s}^{-1}$, right heart catheterisation was performed and the diagnosis of $\mathrm{PH}$ was confirmed if mean pulmonary artery pressure was $\geqslant 25 \mathrm{mmHg}$. The Dana Point classification was used $[1,9]$. A standardised diagnostic work-up was used in $\mathrm{PH}$ cases: thoracic computed tomography scan, hepatic echography, lung function tests, genetic screening, screening for systemic diseases, and HIV serology were used when appropriate.

At the beginning of our study, our database included 86 prevalent $\mathrm{PH}$ patients. Over the next 3 yrs, 126 incident $\mathrm{PH}$ patients were referred. Median age at inclusion was $2.4 \mathrm{yrs}$ (range 0.5-15 yrs); there were 120 (56\%) females and 92 males. Mean pulmonary artery pressure was $55 \pm 16 \mathrm{mmHg}$, pulmonary vascular resistance was $16 \pm 7$ Wood units and cardiac index was $3.6 \pm 1.2 \mathrm{~L} \cdot \mathrm{min} \cdot \mathrm{m}^{-2}$. Distribution of $\mathrm{PH}$ causes for the 212 patients are shown in the table 1 .

First, the proportion of pulmonary arterial hypertension (PAH) in our series (75\%) is lower than in the recently published TOPP (Tracking Outcomes and Practice in Paediatric Pulmonary hypertension; $82 \%$ ) or REVEAL (Registry to EValuate Early And Long term PAH disease; 92\%) registries [6, 7]. In addition, the distribution within the subgroups of PAH is also different; idiopathic PAH (iPAH) was present in $16 \%$ versus $53 \%$ in TOPP and $56 \%$ in REVEAL $[6,7]$. Our results more closely match those observed in the Netherlands national registry $(23 \% \mathrm{iPAH}$ and $72 \% \mathrm{PAH}$ associated with congenital heart disease) [4]. The higher proportion of $\mathrm{PAH}$ observed in multinational registries is most likely due to the fact that these patients are referred to

\section{TABLE 1 Classification of pulmonary hypertension (PH)}

\begin{tabular}{|c|c|c|c|}
\hline Classification & Prevalence $^{\#}$ & Incidence & Change \\
\hline 1 Pulmonary arterial hypertension & $75(87.2)$ & $85(67.5)$ & $\times 1.2$ \\
\hline 1.2 Heritable & $2(2.3)$ & $4(3.2)$ & \\
\hline \multicolumn{4}{|l|}{ 1.2.1 BMPR2 } \\
\hline \multicolumn{4}{|l|}{ 1.2.2 ALK1, endoglin } \\
\hline \multicolumn{4}{|l|}{ 1.4 Associated with } \\
\hline \multicolumn{4}{|l|}{ 1.4.1 Connective tissue disease } \\
\hline \multicolumn{4}{|l|}{ 1.4.2 HIV infection } \\
\hline \multicolumn{4}{|l|}{ 1.4.3 Portal hypertension } \\
\hline 1.4.4 Congenital heart disease & $58(67.5)$ & $64(51)$ & \\
\hline \multicolumn{4}{|l|}{ 1.4.5 Schistosomiasis } \\
\hline 2 PH due to left heart disease & $2(2.3)$ & $4(3.2)$ & $\times 2$ \\
\hline $3 \mathrm{PH}$ due to lung disease and/or hypoxia & $6(7)$ & $24(19)$ & $\times 4$ \\
\hline \multicolumn{4}{|l|}{ 3.1 Chronic obstructive pulmonary disease } \\
\hline 3.2 Interstitial lung disease & & 5 & \\
\hline 3.3 Other pulmonary diseases with mixed restrictive and obstructive pattern & & 4 & \\
\hline \multicolumn{4}{|l|}{ 3.4 Sleep-disordered breathing } \\
\hline 3.5 Alveolar hypoventilation disorders & 2 & 11 & \\
\hline \multicolumn{4}{|l|}{ 3.6 Chronic exposure to high altitude } \\
\hline 3.7 Developmental abnormalities & 4 & 4 & \\
\hline \multicolumn{4}{|l|}{4 Chronic thromboembolic $\mathrm{PH}$} \\
\hline $5 \mathrm{PH}$ with unclear and/or multifactorial mechanisms & $3(3.5)$ & $13(10.3)$ & $\times 4.3$ \\
\hline 5.1 Haematological disorders: myeloproliferative disorders and splenectomy & 3 & 11 & \\
\hline
\end{tabular}

Data are presented as $\mathrm{n}(\%)$ or $\mathrm{n}$, unless otherwise stated. BMPR2: bone morphogenetic protein receptor type II; ALK1: activin receptor-like kinase-1. \#: $\mathrm{n}=86$; ${ }^{\text {: }} \mathrm{n}=126$ Reproduced with modification from [1] with permission from the publisher. 
expert centres to be treated with advanced therapies whereas congenital heart disease associated with $\mathrm{PAH}$ patients aggregate in paediatric cardiac centres such as ours.

Secondly, we observed a four-fold larger proportion of incident patients in Group 3 (PH due to lung disease and/or hypoxia). This emerging problem was also pointed out in the TOPP registry [7]. The apparent increase in incidence of these patients is probably due to enhanced screening strategies in infants with lung disease and to closer collaborations between paediatric cardiologists and pulmonologists. Survival of congenital diaphragmatic hernia has increased considerably over the last few years, reaching $60 \%$ in reference centres but $\mathrm{PH}$ is a common complication and its severity predicts the outcome [10]. Within this group, $30 \%$ of patients had congenital diaphragmatic hernia and $33 \%$ had bronchopulmonary dysplasia. This proportion may still be an underestimate as bronchopulmonary dysplasia is more frequent in developing countries which do not generally participate in large registries. Similarly, the proportion of $\mathrm{PH}$ due to PAH associated with congenital heart disease is probably different in different regions of the world.

Furthermore, paediatric $\mathrm{PH}$ patients may have multiple contributing pathologies and therefore the Dana Point classification can be imprecise. In our series, for example, 22 patients could have been classified in another Dana Point group because of co-existing pathologies (lung disease but without hypoxia and/or small cardiac defects, genetic, metabolic or other associated diseases). Indeed those patients would have been classified according to the Panama classification [11] in category 6 (multifactorial pulmonary hypertensive vascular disease in congenital malformation syndromes) or 10 (paediatric pulmonary vascular disease associated with other system disorders). Finally the number of patients in Group 3 is somewhat limited by the fact that advanced $\mathrm{PH}$ therapies are not approved in this group and they are therefore often not referred to "expert centres". This may change in the future as dedicated trials will be developed to evaluate efficacy and safety of PH drugs in these patients, usually in larger referral centres.

We also observed a four-fold higher proportion in Group 5 patients, in the incidence compared to the prevalence group (PH with unclear and/or multifactorial mechanisms). This proportion of $7.5 \%$ is different to TOPP $(1 \%)$ or REVEAL $(<1 \%)$ and the Dutch registry $(0 \%)$. This increase in Group 5 may have several explanations: incorrect classification elsewhere because of limitation of available diagnostic data or a truly new emerging group related to our local screening strategy for $\mathrm{PH}$ in rare paediatric diseases (such as cancer, immune defects and inborn errors of metabolism). This screening strategy is related to our multidisciplinary approach across 32 nationally designated reference centres for rare paediatric diseases. Also, for the same reason as in Group 3, these patients may be underdiagnosed, not referred to expert centres and therefore do not appear in registries.

Our data clearly show that the full picture of the aetiologies of paediatric $\mathrm{PH}$ cannot be described through large registries outlining incidences in selected participating centres. Information from national centralised registries (Dutch and $\mathrm{UK})$, multicentre registries and tertiary expert paediatric $\mathrm{PH}$ centres are complementary for this purpose. Thus, the aetiology and consequently epidemiology of paediatric $\mathrm{PH}$ probably varies according to countries involved in registries (particularly the proportion of participating centres from developing countries) and further according to the health system involved (for example, if it has expert PH referral centres or not, or planned screening programmes in certain associated disease states).

Finally it appears obvious that the distribution of aetiologies described in different registries is related, at least in part, to the availability of $\mathrm{PH}$ specific treatments, for some but not all possible indications. Such treatments have allowed major progress in the management of children with $\mathrm{PAH}$; however, different availability patterns introduce inevitable biases into the types of patients reported in different types of registries.

It is clear that a new paediatric $\mathrm{PH}$ population is emerging. Building dedicated international registries that attempt to solve some of the issues raised in this letter is an important challenge for the future.

\section{Marilyne Lévy*, David Celermajer", Isabelle Szezepanski*, Younes Boudjemline* and Damien Bonnet*}

*Centre de référence M3C, Paediatric Cardiology, Université Paris Descartes, Sorbonne Paris Cité, Hôpital Necker Enfants Malades, Paris, France. "Sydney Medical Schools, University of Sydney, Sydney, Australia.

Correspondence: M. Lévy, Service de Chirurgie Cardiaque Pédiatrique, 149 rue de Sèvres, 75015 Paris, France. E-mail: marilyne.levy@nck.aphp.fr

Statement of Interest: Statements of interest for M. Lévy and D. Bonnet can be found at www.erj.ersjournals.com $/$ site $/ \mathrm{misc} /$ stements.xhtml

\section{REFERENCES}

1 Simonneau G, Robbins IM, Beghetti M, et al. Updated clinical classification of pulmonary hypertension. J Am Coll Cardiol 2009; 54: Suppl. 1, S43-S54.

2 Fraisse A, Jais X, Schleich JM, et al. Characteristics and prospective 2-year follow-up of children with pulmonary arterial hypertension in France. Arch Cardiovasc Dis 2010; 103: 66-74.

3 Moledina S, Hislop AA, Foster $\mathrm{H}$, et al. Childhood idiopathic pulmonary arterial hypertension: a national cohort study. Heart 2010; 96: 1401-1406.

4 van Loon RL, Roofthooft MT, Hillege HL, et al. Pediatric pulmonary hypertension in the Netherlands: epidemiology and characterization during the period 1991 to 2005. Circulation 2011; 124: 1755-1764.

5 Fasnacht MS, Tolsa JF, Beghetti M. The Swiss registry for pulmonary arterial hypertension: the paediatric experience. Swiss Med Wkly 2007; 137: 510-513.

6 Barst RJ, McGoon MD, Elliott CG, et al. Survival in childhood pulmonary arterial hypertension: insights from the registry to evaluate early and long-term PAH disease management. Circulation 2012; 125: 113-122.

7 Berger RM, Beghetti M, Humpl T, et al. Clinical features of paediatric pulmonary hypertension: a registry study. Lancet 2012; 379: 537-546.

8 Barst RJ, Ertel SI, Beghetti M, et al. Pulmonary arterial hypertension: a comparison between children and adults. Eur Respir J 2011; 37: 665-677. 
9 Galiè N, Hoeper MM, Humbert M, et al. Guidelines for the diagnosis and treatment of pulmonary hypertension. Eur Respir J 2009; 34: 1219-1263.

10 Kotecha S, Barbato A, Bush A, et al. Congenital diaphragmatic hernia. Eur Respir J 2012; 39: 820-829.
11 Cerro MJ, Abman S, Diaz G, et al. A consensus approach to the classification of pediatric pulmonary hypertensive vascular disease: report from the PVRI Pediatric Taskforce, Panama 2011. Pulm Circ 2011; 1: 286-298.

DOI: $10.1183 / 09031936.00114212$

\section{The anti-IL-17A antibody secukinumab does not attenuate ozone-induced airway neutrophilia in healthy volunteers}

\section{To the Editor:}

Within the lung the T-helper cell interleukin (IL)-17 (also referred to as IL-17A) is recognised as one of the principal cytokines that links the activation of T-lymphocytes to the chronic accumulation of neutrophils. It has been proposed that IL-17A is a relevant pharmacological target in inflammatory lung diseases with sustained mobilisation of neutrophils [1].

Secukinumab (AIN457; Novartis Healthcare Pvt. Ltd, Basel, Switzerland) is a recombinant high-affinity fully human

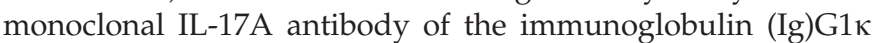
isotype, which binds to human IL-17A and neutralises the bioactivity of this cytokine [2].

Ozone exposure in healthy volunteers induces an acute and reproducible neutrophilic airway inflammation, which can be utilised as a pharmacological model to test anti-inflammatory drugs in early development [3-5].

We performed a single centre, phase II, double-blind, placebocontrolled, parallel-group study with an open label reference arm, investigating the ability of secukinumab to attenuate airway neutrophilia in induced sputum $24 \mathrm{~h}$ and $48 \mathrm{~h}$ following ozone exposure in healthy volunteers. Subjects underwent a $3 \mathrm{~h}$ ozone challenge, and induced sputum samples were collected $24 \mathrm{~h}$ and $48 \mathrm{~h}$ after the challenge. Subjects with an inflammatory response to ozone (as reflected by an increase in the total number of sputum neutrophils by at least $50 \%$ compared with the screening visit) were then randomised to receive either secukinumab (10 $\mathrm{mg} \cdot \mathrm{kg}^{-1}$ bodyweight) or placebo, in a double blind fashion administered as an infusion over 120 mins or to an open-label single-dose oral corticosteroid treatment (OCS, $50 \mathrm{mg}$ ) in the ratio of 2:1:1 (secukinumab:placebo:OCS).

The secukinumab/placebo treatment period consisted of a single dosing visit on day 8 followed by an ozone challenge 1 week later on day 15 and subsequent sputum inductions on day 16 and day 17. A third ozone challenge was performed on day 36 in the first nine subjects and on day 64 in the second nine subjects assigned to secukinumab or placebo. Subjects assigned to OCS treatment received a single dose treatment $1 \mathrm{~h}$ before the start of the ozone challenge on day 15. Sputum induction followed $24 \mathrm{~h}$ and $48 \mathrm{~h}$ after the challenge.
The Ethical Committee of Schleswig-Holstein, Germany approved the study and all subjects provided written informed consent.

The inhalation of $250 \mathrm{ppb}$ ozone and processing of sputum was performed as previously described [3-5].

Secukinumab concentrations in serum were determined by a competitive ELISA assay. Safety assessments and an assessment of immunogenicity to secukinumab were performed at various visits.

The study tested the null hypothesis of no difference between the secukinumab and placebo group in total number of neutrophils in induced sputum $24 \mathrm{~h}$ after ozone. Post hoc power assumptions using the observed standard deviation of $4.2 \times 10^{6} \cdot \mathrm{mL}^{-1}$ showed that 12 and 6 subjects in the secukinumab and placebo groups, respectively, provide $80 \%$ power to detect a difference of $5.5 \times 10^{6} \cdot \mathrm{mL}^{-1}$ using a two-sided test at $10 \%$ alpha. Standard ANCOVA methods, including baseline adjustment, were applied to neutrophil counts. Data were log-transformed to achieve a normal distribution. No alpha adjustments were made.

24 Caucasian subjects (19 males and five female with mean: age $40 \mathrm{yrs}$ and body mass index $24.2 \mathrm{~kg} \cdot \mathrm{m}^{-2}$ ) were enrolled in the study, of which 23 subjects completed the study. One subject was withdrawn for administrative reasons. The mean sputum neutrophil count at screening was $0.63 \times 10^{6} \mathrm{~mL}^{-1}$ and increased to $4.19 \times 10^{6} \mathrm{~mL}^{-1}$ after the baseline ozone challenge.

Regarding the primary end-point in this study, there was no significant difference observed between the treatment groups in the change from baseline in the total number of sputum neutrophils $24 \mathrm{~h}$ after the day 15 ozone challenge (day 16) (fig. 1). Sputum neutrophil counts were higher in secukinumaband OCS-treated subjects when compared with those receiving placebo $48 \mathrm{~h}$ after day 15 ozone challenge (day 17), with the latter reaching statistical significance. There was no significant effect of either secukinumab or placebo on the change from baseline in total number of neutrophils in induced sputum $24 \mathrm{~h}$ or $48 \mathrm{~h}$ after day 36 or day 64 challenges, with the exception of secukinumab-treated subjects $48 \mathrm{~h}$ after the day 64 challenge; driven by an unusually high number of sputum neutrophils in the placebo group. Evaluation of the change from baseline in the per cent of neutrophils did not reveal any treatment effects at any of the time points (data not shown). 